Research article

\title{
Overexpression of Mitogen-activated protein kinase phosphatase-3 (MKP-3) reduces FoxO1 phosphorylation in mice hypothalamus
}

\author{
Bárbara de Almeida Rodrigues ${ }^{\mathrm{a}, 1}$, Gabriel Keine Kuga ${ }^{\mathrm{b}, 1}$, Vitor Rosetto Muñoz ${ }^{\mathrm{a}}$, \\ Rafael Calais Gaspar ${ }^{\mathrm{a}}$, Mariana Rosolen Tavares ${ }^{\mathrm{a}}$, José Diego Botezelli ${ }^{\mathrm{a}}$, \\ Adelino Sanchez Ramos da Silva ${ }^{c}$, Dennys Esper Cintra ${ }^{a}$, Leandro Pereira de Moura ${ }^{a}$, \\ Fernando Moreira Simabuco ${ }^{a}$, Eduardo Rochete Ropelle ${ }^{a}$, José Rodrigo Pauli, ${ }^{\mathrm{a}, *}$ \\ a School of Applied Sciences, University of Campinas, Limeira, SP, Brazil \\ b Post-Graduate Program in Movement Sciences, São Paulo State University (Unesp), Institute of Biosciences, Rio Claro, Sao Paulo, Brazil \\ ${ }^{c}$ School of Physical Education and Sport of Ribeirao Preto, University of Sao Paulo, Ribeirao Preto, Sao Paulo, Brazil
}

\section{A R T I C L E I N F O}

\section{Key-words:}

MKP-3

Insulin

Hypothalamus

\begin{abstract}
A B S T R A C T
The mitogen-activated kinase phosphatase-3 (MKP-3) has gained great importance in the scientific community by acting as a regulator of the cell cycle through dephosphorylation of FoxO1, an important transcription factor involved in the insulin intracellular signaling cascade. When dephosphorylated and translocated to the nuclei, FoxO1 can promote the transcription of orexigenic neuropeptides (NPY/AgRP) in the hypothalamus, whereas insulin signaling is responsible for the disruption of this process. However, it is not understood if the hypothalamic activation of MKP-3 affects FoxO1 phosphorylation, and we hypothesized that MKP-3 overexpression reduces the capacity of the insulin signal to phosphorylate FoxO1. In the present study, we overexpressed the DUSP6 gene through an injection of adenovirus directly into the hypothalamic third ventricle of Swiss mice. The colocalization of the adenovirus was confirmed by the immunofluorescence assay. Then, MKP-3 overexpression resulted in a significant reduction of hypothalamic FoxO1 phosphorylation after insulin stimulation. This effect was independent of changes in Akt phosphorylation. Thus, the role of MKP-3 in the hypothalamus is closely associated with FoxO1 dephosphorylation and may provide a potential therapeutic target against hypothalamic disorders related to obesity and unbalanced food intake control.
\end{abstract}

\section{Introduction}

The hypothalamus acts as an important structure for metabolic control by regulating energy homeostasis through stimuli from the endocrine system [1-4]. In this context, insulin is an important regulator of energy homeostasis triggering a complex network of interactions between intracellular proteins [3]. At the molecular level, insulin receptor (IR) activation by insulin promotes tyrosine phosphorylation of insulin receptor substrates-1 and 2 (IRS-1 and 2), increasing the activity of the pathway phosphatidylinositol-3-kinase (PI3k)/Protein kinase B (Akt) $[1,3]$. This pathway promotes the anorectic effect of insulin through the phosphorylation and inactivation of Forkhead transcriptional factor class $\mathrm{O} 1$ (FoxO1), releasing it from the cellular nucleus for further proteasomal degradation. This process inhibits the transcriptional activity of orexigenic neuropeptides such as
Neuropeptide Y (NPY) and Agouti-related Protein (AgRP) [1,4,5].

On the other hand, the mitogen-activated kinase phosphatase-3 (MKP-3), also known as DUSP6, acts as an important regulator of the cell cycle through its dephosphorylating activity [6]. Among the MKP-3 target proteins are FoxO1 [7-10], extracellular signal-regulated kinase (ERK) $[9,11,12]$ and c-Jun N-terminal kinase (JNK) [6,11], which are involved in the insulin signaling pathway. Especially, FoxO1 phosphorylation has been demonstrated as one of the main mechanisms by which insulin propagates the signs of satiety [10]. In the liver, it has been previously described that MKP-3 is an important activator of FoxO1, which increases the transcription of genes involved in hepatic glucose production [7,8,12]. Thus, a fine interaction between MKP-3 activity and the insulin pathway may occur at the hypothalamic level, which is an important insulin action site. Therefore, understanding the phosphatase activity of MKP-3 is extremely important to develop new

* Corresponding author at: School of Applied Sciences, University of Campinas (UNICAMP), R. Pedro Zaccaria, 1300 Caixa Postal 1068, Jd. Sta. Luzia, CEP 13484-350, Limeira, Sao Paulo, Brazil.

E-mail address: rodrigopaulifca@gmail.com (J.R. Pauli).

${ }^{1}$ These authors contributed equally to this work. 
strategies against diseases associated with dysregulation of these molecular pathways, such as obesity and type 2 diabetes mellitus.

Nevertheless, studies investigating the activity of MKP-3 in vitro indicated different substrate preferences according to the type of cell and the physiological conditions [11]. Also, few tissues demonstrated MKP-3 activity in vivo $[7,8,12,13]$, which hampers the identification of triggers for the activation of this protein and its behavior in different tissues. The knowledge regarding MKP-3 action on the hypothalamus under insulin stimuli is quite limited, despite the great importance of this structure and hormone for metabolism. Thus, the objective of the present study was to investigate the possible phosphatase activity exerted by MKP-3 on FoxO1 in the mouse hypothalamus after insulin administration. In this way, we hypothesized that MKP-3 overexpression reduces the capacity of the insulin signal to phosphorylate hypothalamic FoxO1.

\section{Materials and methods}

\subsection{Cell culture}

HEK293 cells were used for the production of the adenoviral vectors. The cells were cultured in Dulbecco's Modified Eagle's medium (DMEM), supplemented with 10\% Fetal Bovine Serum (FBS), $0.1 \mathrm{U} / \mathrm{ml}$ penicillin and $0.1 \mu \mathrm{g} / \mathrm{mL}$ streptomycin, and then incubated at $37^{\circ} \mathrm{C}$ in an atmosphere containing $5 \% \mathrm{CO}_{2}$.

\subsection{Adenoviral vectors}

The viral vectors used were replication-deficient type 5 adenoviruses and the MKP-3 gene was cloned between the NheI and BamHI restriction sites in the pGEM vector (Promega). Then, the MKP-3 gene was subcloned into the pShires vector (provided by Prof. Dr. Armando Morais Ventura, University of São Paulo), which allows further cloning into the adenoviral vector pAdeno-X (Clontech), using the I-CeuI and PISceI sites. This vector ensures the co-expression of the GFP (enhanced Green Fluorescent Protein) reporter gene though an IRES element, allowing the identification of the transfected or transduced cells. Later, the adenoviral vectors were constructed using the Adeno- $\mathrm{X}^{\mathrm{TM}}$ Expression System 1 kit (Clontech). Briefly, the adenoviruses were obtained by transfection of the linearized pAdeno-X vectors in HEK293 cells, followed by purification of adenoviral particles by the Fast-Trap Adenovirus Purification and Concentration Kit (Millipore) and the determination of the number of adenoviral particles by the end-point method. Cdc2-like kinase 2 in the hypothalamus is necessary to maintain energy homeostasis [22].

\subsection{End-point dilution assay}

To determine the number of viral particles by end-point dilution, HEK293 cells spread in 96-well plates were used. The purified viruses were diluted in culture medium and applied to the first wells of the plates using a 1:100 ratio. Then, serial dilutions were performed using a ratio of $1: 10$ to $1: 10^{14}$, and for each adenovirus, eight replicates were made. The virus titers were calculated using the formula: $\mathrm{T}=10$ $[1+(S-0.5)]$, where $S=$ sum of the proportions of cell death for each dilution. The protocol was adapted from the guidelines in the Adeno- $\mathrm{X}^{\mathrm{TM}}$ Expression System 1 (Clontech) manual.

\subsection{Animals}

Four-week-old (15-20 g) Swiss male mice, were housed in individual cages with free access to water and standard commercial feed (Presence ${ }^{\circ}$ ) in a controlled environment at a temperature of $21{ }^{\circ} \mathrm{C} \pm 2$ and a $12 / 12 \mathrm{~h}$ light/dark photoperiod. The experimental procedures were approved by the Animal Use Ethics Committee of the State University of Campinas (Process 4064-1).

\subsection{Stereotaxic surgery and adenoviral vector injection}

The animals were anesthetized with an intraperitoneal injection of chlorohydrate of ketamine $(100 \mathrm{mg} / \mathrm{kg})$ and xylazine $(5 \mathrm{mg} / \mathrm{kg})$. After this, the animals were positioned on the Stoelting stereotaxic apparatus. Then, after trichotomy and antisepsis of the cranial region, we performed an inter-parietal incision of approximately $1 \mathrm{~cm}$ extension. Also, we utilized Hamilton $100 \mu \mathrm{L}$ syringes to perform the injection $(1 \mu \mathrm{L})$ of the MKP-3 and GFP adenoviral vectors to reach the third hypothalamic ventricle $(1.8 \mathrm{~mm}$ posterior to the bregma and $5.0 \mathrm{~mm}$ below the surface of the skull) [14]. At the end of the surgical procedure, the animals received paracetamol diluted in water $(78 \mathrm{mg} / \mathrm{kg}$ ) and, after 5 days, a new stereotaxic surgery was realized for intracerebroventricular (i.c.v.) injection of insulin $(200 \mathrm{mU})$ following the same coordinates. Five minutes after insulin injection, the animals were euthanized for the initiation of molecular analyses.

\subsection{Immunofluorescence staining}

The animals were deeply anesthetized using pentobarbital administration (50 $\mathrm{mg} \mathrm{kg}^{-1}$ ) and perfused with PBS (0.1 M PBS, pH 7.4, 0.9\% saline), followed by $4 \%$ paraformaldehyde in $0.1 \mathrm{M}$ phosphate buffer, $\mathrm{pH}$ 7.4. The brain was extracted and placed in a solution containing $4 \%$ paraformaldehyde and $0.1 \mathrm{M}$ phosphate buffer at $4{ }^{\circ} \mathrm{C}$ for two hours and transferred to solutions containing $20 \%, 30 \%$, and $40 \%$ sucrose in $0.1 \mathrm{M}$ phosphate buffer, $\mathrm{pH}$ 7.4. The brain was soaked in Tissue-Tek OCT compound (Sakura Finetek, Torance, CA), sectioned in a cryostat producing $30 \mu \mathrm{m}$ slices, and placed in cryoprotectant solution (PBS [0.1 M PBS, pH 7.4, 0.9\% saline], Ethylene glycol, glycerol). The sections were incubated with specific primary antibodies, then with fluorophore-tagged secondary antibodies and placed on pre-treated poly-L-lysine slides for tissue adhesion. They were covered with coverslips and visualized on a Leica DMI 4000 B immunofluorescence microscope using an image capture system.

\subsection{Hypothalamus extraction and immunoblotting analysis}

The immunoblotting method was previously described $[15,16]$. The following antibodies were used: anti-Akt (rabbit, sc-8312, Santa Cruz Biotechnology), anti-phospho-Akt (Ser473) (rabbit, sc-101629, Santa Cruz Biotechnology), anti- $\beta$-actin (rabbit, 4967s, Cell Signaling Technology, MA), anti-FoxO1 (rabbit, 9454s, Cell Signaling Technology, MA), anti-phospho-FoxO1 (Ser256) (rabbit, 9461s, Cell Signaling Technology, MA), and anti-MKP-3 (rabbit, bs-11546R, Bioss). The specific bands were detected by enhanced chemiluminescence reagent (ECL) and consequent exposure on RX (Kodak ${ }^{\circ}$ ) films and quantified by densitometry (UN-SCAN-IT gel 6.1).

\subsection{Statistical analysis}

Data were expressed as mean \pm SEM followed by the indicated number of experiments. For all analyses, a $t$-test was used with a significance level of 0.05 .

\section{Results}

\subsection{Overexpression of MKP-3 on HEK293Cells}

In order to characterize the dephosphorylating activity of the MKP-3 targeting other proteins, we overexpressed the MKP-3 in HEK293 cells. The MKP-3 gene (DUSP6 gene) was cloned into the pGEM vector (Promega) followed by subcloning the same genes into the pShires vector. After observing in a fluorescence microscope the co-expression of the GFP reporter gene in the analyzed samples, cloning of the MKP-3 genes in the pShires vectors was tested by immunoblotting (see Fig. 1A in Overexpression of Mitogen-activated protein kinase phosphatase-3 

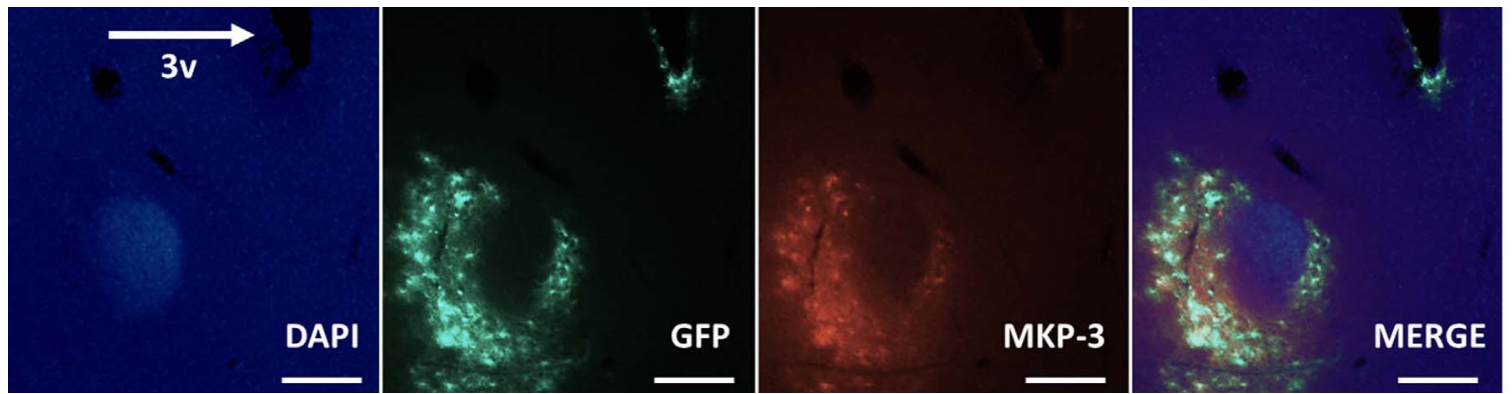

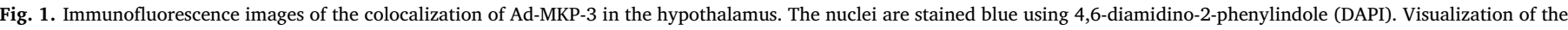

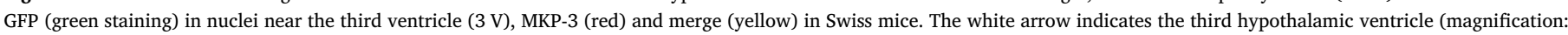
$20 \times$, scale bars represent $200 \mu \mathrm{m}$ )

(MKP-3) reduces FoxO1 phosphorylation in HEK293 cells, Rodrigues et al., Data in Brief, submitted). The next step was to perform the subcloning of the MKP-3 genes into adenoviral vectors through the I-CeuI and PI-SceI sites in the pAdeno-X vector. Thus, the expression of these vectors was tested by transfection of pAdeno-X-MKP-3 into HEK293 cells (see Fig. 1B in Overexpression of Mitogen-activated protein kinase phosphatase-3 (MKP-3) reduces FoxO1 phosphorylation in HEK293 cells, Rodrigues et al., Data in Brief, submitted). After the expression was confirmed, the adenoviral vectors were purified. The adenoviral vectors titers obtained were: $2.9 \times 10^{-9} \mathrm{PFU} / \mu \mathrm{L}$ (Ad-MKP-3) and $1 \times 10^{9}$ PFU/ $\mu L$ (Ad-GFP).

\subsection{Overexpression of MKP-3 in the hypothalamus of swiss mice}

After the adenovirus purification, we performed a microinjection of the adenoviral vectors in the hypothalamus of Swiss mice. To confirm the injection, the localization of the GFP reporter protein was verified in the region of the third ventricle confirming the increase of MKP-3 expression in the region of interest (Fig. 1). In relation to the phosphorylation of the proteins involved with MKP-3 phosphatase activity in vivo, we verified that the injection of MKP-3 adenovirus reduced FoxO1 phosphorylation. This fact demonstrates an important role of MKP-3 on the dephosphorylation of FoxO1, a key protein involved in energy metabolism, in vivo (Fig. 2). In addition, there was no difference between the groups for Akt phosphorylation, indicating that there is no interference of the increase of MKP-3 on Akt phosphorylation.

\section{Discussion}

This study evaluated the effects of MKP-3 overexpression in mice hypothalamus targeting its phosphatase action on FoxO1. Transfection of HEK293 cells with the pShires vector carrying MKP-3 was found to increase the MKP-3 content (see Fig. 1A in Overexpression of Mitogenactivated protein kinase phosphatase-3 (MKP-3) reduces FoxO1 phosphorylation in HEK293 cells, Rodrigues et al., Data in Brief, submitted).
Likewise, after the adenovirus purification was performed, Ad-MKP-3 and Ad-GFP were injected directly into the hypothalamus of Swiss mice. Firstly, to confirm the microinjection in the region of interest, we performed immunofluorescence analysis of the affected hypothalamic region, whereby it was possible to observe the colocalization of Ad-GFP and Ad-MKP-3 in the region of the third ventricle. Therefore, we investigated the effects of MKP-3 overexpression on FoxO1 phosphorylation after insulin stimulus in the hypothalamus of mice that received adenoviral vector microinjection carrying only GFP or MKP-3. There was lower phosphorylation of FoxO1 in vivo after insulin stimulation of the hypothalamus with MKP-3 overexpression. The reduction in pFoxO1 occurred independently of changes in Akt phosphorylation, suggesting the role of MKP-3 in dephosphorylating FoxO1. Activation of Akt contributes to various biological processes including regulation of FoxO1 and food intake. Akt can phosphorylate and exclude the FoxO1 from the nucleus and lead FoxO1 to proteasomal degradation, and these molecular events can inhibit FoxO1-induced orexigenic signals in the hypothalamus [12,14,17].

The knowledge about the hypothalamic action of MKP-3 is extremely important because there is limited evidence about the role of this protein in the central nervous system. It has been shown that animals with a global deletion of MKP-3 and exposed to a high fat diet reduced serum glucose levels, body weight and liver triglycerides, but increased insulin sensitivity and energy expenditure when compared to wild type animals kept on the same diet [13]. Due to the fact that MKP3 is increased in liver $[7,8,18]$ and possibly in other tissues, including the hypothalamus, under conditions of metabolic disorders such as obesity, investigations regarding therapeutic interventions are necessary.

According to our findings, a substrate of MKP-3 action is FoxO1, which seems to play biological effects according to the population of hypothalamic neurons investigated. It was evidenced that the deletion of FoxO1 in Sf-1 neurons of the ventromedial nucleus of the hypothalamus resulted in increased energy expenditure, glucose tolerance, and insulin sensitivity [19]. In addition, other studies in POMC neurons,
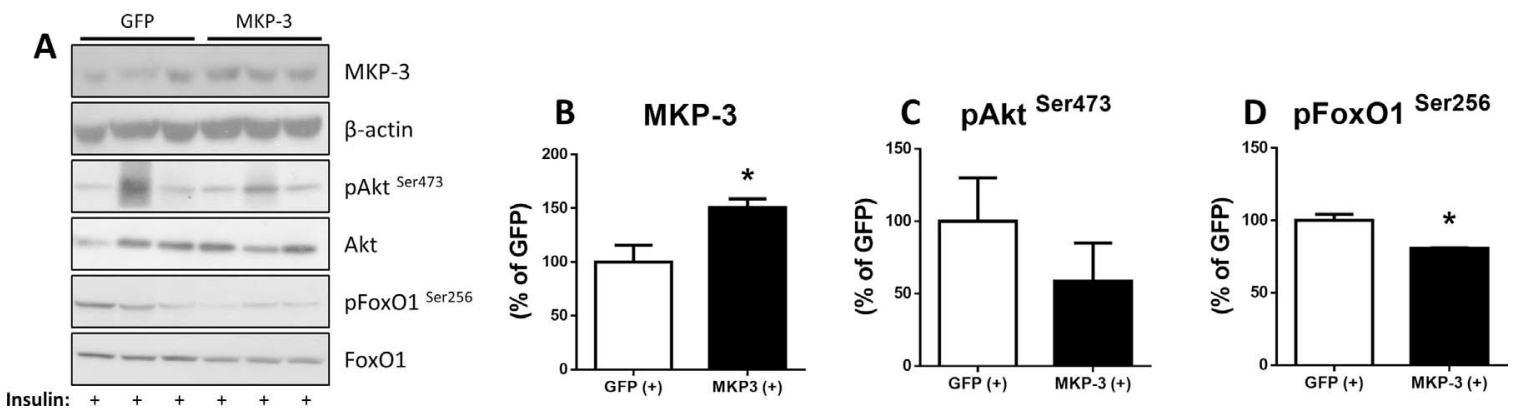

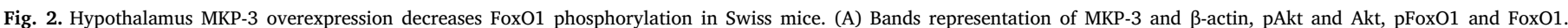

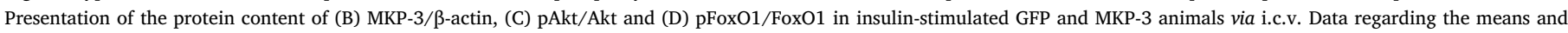
standard deviation of each experimental group, of two experiments in triplicate, * $P<0.05 v s$ GFP $(+)$; (GFP, $n=3)$; (MKP-3, $n=3$ ). 
which are essential for food intake control [20], can provide substantial evidence as to whether MKP-3 can modulate, through FoxO1, the transcription of neuropeptides related to food intake control. This possibility is supported by the demonstration that activation or overexpression of FoxO1 in the hypothalamus increased food intake and body weight $[1,4]$. Moreover, the inhibition of hypothalamic FoxO1 expression in rats with diet-induced obesity improved insulin sensitivity, and reduced dietary intake, body mass, and insulinemia [21]. Thus, the role of MKP3 in this context is very important, because the hypothalamus is a key organ for the maintenance of energy homeostasis and FoxO1 deregulation occurs under conditions of metabolic syndrome, obesity and Type 2 diabetes mellitus (1-3).

In summary, the present study evidenced that the increase in MKP-3 content in the mouse hypothalamus is associated with a marked decrease in FoxO1 phosphorylation after insulin stimulation. This evidence shows that MKP-3 protein may induce hypothalamic FoxO1 dephosphorylation. Therefore, further investigations should evaluate the phosphatase activity of MKP-3 and the repercussions for energetic homeostasis. Finally, the expression of MKP-3 should be investigated in the condition of obesity and other metabolic syndromes (with insulin and leptin resistance). The understanding of these mechanisms is necessary for the development of effective strategies in situations of pathologies involving the deregulation of this molecular pathway. This is a descriptive study that provides, for the first time, evidence of MKP-3 hypothalamic action in vivo, and FoxO1 can be a substrate for this protein.

\section{Author contributions}

B.A.R. was responsible for the experimental design, the data collection and the manuscript writing. G.K.K. and J.D.B. were responsible for the data collection, the data analysis and the manuscript writing. B.A.R. and M.R.T. were responsible for the adenovirus construction, the cell culture and the immunofluorescence assay. V.R.M. and R.C.G. were responsible for the manuscript review, the data analysis and the figures preparation. A.S.R.S, L.P.M., F.M.S. and E.R.R. was responsible for data analysis, the manuscript design and the manuscript review. J.R.P. was responsible for the research funding, data analysis, manuscript design and final review. All authors approve this submission and are in accordance to the journal guidelines.

\section{Acknowledgements}

The present work was received financial support of the São Paulo Research Foundation (FAPESP - process number 2016/18488-8 and 2013/25512-4). The authors thank Armando Ventura for providing pShires vector and JRR da Silva for the support given during the experiments.

\section{References}

[1] H.-J. Kim, M. Kobayashi, T. Sasaki, O. Kikuchi, K. Amano, T. Kitazumi, Y.-S. Lee, H. Yokota-Hashimoto, V.Y. Susanti, Y.I. Kitamura, J. Nakae, T. Kitamura, Overexpression of FoxO1 in the hypothalamus and pancreas causes obesity and glucose intolerance, Endocrinology 153 (2012) 659-671, http://dx.doi.org/10. 1210/en.2011-1635.

[2] E.P. Araujo, J.C. Moraes, D.E. Cintra, L.A. Velloso, MECHANISMS IN ENDOCRINOLOGY: hypothalamic inflammation and nutrition, Eur. J. Endocrinol. 175 (2016) R97-R105, http://dx.doi.org/10.1530/EJE-15-1207.

[3] K. Muta, D.A. Morgan, K. Rahmouni, The role of hypothalamic mTORC1 signaling in insulin regulation of food intake, body weight, and sympathetic nerve activity in male mice, Endocrinology 156 (2015) 1398-1407, http://dx.doi.org/10.1210/en. 2014-1660.

[4] M.-S. Kim, Y.K. Pak, P.-G. Jang, C. Namkoong, Y.-S. Choi, J.-C. Won, K.-S. Kim, S.-
W. Kim, H.-S. Kim, J.-Y. Park, Y.-B. Kim, K.-U. Lee, Role of hypothalamic Foxo1 in the regulation of food intake and energy homeostasis, Nat. Neurosci. 9 (2006) 901-906, http://dx.doi.org/10.1038/nn1731.

[5] T. Kitamura, Y. Feng, Y. Ido Kitamura, S.C. Chua, A.W. Xu, G.S. Barsh, L. Rossetti, D. Accili, Forkhead protein FoxO1 mediates Agrp-dependent effects of leptin on food intake, Nat. Med. 12 (2006) 534-540, http://dx.doi.org/10.1038/nm1392.

[6] A. Jurek, K. Amagasaki, A. Gembarska, C.-H. Heldin, J. Lennartsson, Negative and positive regulation of MAPK phosphatase 3 controls platelet-derived growth factorinduced Erk activation, J. Biol. Chem. 284 (2009) 4626-4634, http://dx.doi.org/ 10.1074/jbc.M808490200.

[7] L.S.S. Pauli, E.C.C. Ropelle, C.T. de Souza, D.E. Cintra, A.S.R. da Silva, B. de Almeida Rodrigues, L.P. de Moura, R. Marinho, V. de Oliveira, C.K. Katashima, J.R. Pauli, E.R. Ropelle, Exercise training decreases mitogen-activated protein kinase phosphatase-3 expression and suppresses hepatic gluconeogenesis in obese mice, J. Physiol. 592 (2014) 1325-1340, http://dx.doi.org/10.1113/jphysiol.2013. 264002.

[8] Z. Wu, P. Jiao, X. Huang, B. Feng, Y. Feng, S. Yang, P. Hwang, J. Du, Y. Nie, G. Xiao, $\mathrm{H}$. Xu, MAPK phosphatase-3 promotes hepatic gluconeogenesis through dephosphorylation of forkhead box O1 in mice, J. Clin. Invest. 120 (2010) 3901-3911, http://dx.doi.org/10.1172/JCI43250.

[9] C.J. Caunt, S.M. Keyse, Dual-specificity MAP kinase phosphatases (MKPs): shaping the outcome of MAP kinase signalling, FEBS J. 280 (2013) 489-504, http://dx.doi. org/10.1111/j.1742-4658.2012.08716.x.

[10] B. Feng, P. Jiao, Z. Yang, H. Xu, MEK/ERK pathway mediates insulin-promoted degradation of MKP-3 protein in liver cells, Mol. Cell. Endocrinol. 361 (2012) 116-123, http://dx.doi.org/10.1016/j.mce.2012.03.025.

[11] C. Ndong, R.P. Landry, M. Saha, E.A. Romero-Sandoval, Mitogen-activated protein kinase (MAPK) phosphatase-3 (MKP-3) displays a p-JNK-MAPK substrate preference in astrocytes in vitro, Neurosci. Lett. 575 (2014) 13-18, http://dx.doi.org/10.1016/ j.neulet.2014.05.039.

[12] P. Jiao, B. Feng, H. Xu, Mapping MKP-3/FOXO1 interaction and evaluating the effect on gluconeogenesis, PLoS One 7 (2012) e41168, http://dx.doi.org/10.1371/ journal.pone.0041168.

[13] B. Feng, P. Jiao, Y. Helou, Y. Li, Q. He, M.S. Walters, A. Salomon, H. Xu, Mitogenactivated protein kinase phosphatase 3 (MKP-3)-deficient mice are resistant to dietinduced obesity, Diabetes 63 (2014) 2924-2934, http://dx.doi.org/10.2337/db140066.

[14] E.R. Ropelle, M.B. Flores, D.E. Cintra, G.Z. Rocha, J.R. Pauli, J. Morari, C.T. de Souza, J.C. Moraes, P.O. Prada, D. Guadagnini, R.M. Marin, A.G. Oliveira T.M. Augusto, H.F. Carvalho, L.A. Velloso, M.J.A. Saad, J.B.C. Carvalheira, IL-6 and IL-10 anti-inflammatory activity links exercise to hypothalamic insulin and leptin sensitivity through IKKbeta and ER stress inhibition, PLoS Biol. 8 (2010), http://dx. doi.org/10.1371/journal.pbio.1000465.

[15] V.R.R. Silva, T.O. Micheletti, G.D. Pimentel, C.K. Katashima, L. Lenhare, J. Morari, M.C.S. Mendes, D.S. Razolli, G.Z. Rocha, C.T. de Souza, D. Ryu, P.O. Prada, L.A. Velloso, J.B.C. Carvalheira, J. Rodrigo Pauli, D.E. Cintra, E.R. Ropelle, Hypothalamic S1P/S1PR1 axis controls energy homeostasis, Nat. Commun. 5 (2014) 4859, http://dx.doi.org/10.1038/ncomms5859.

[16] V.R. Muñoz, R.C. Gaspar, B.M. Crisol, G.P. Formigari, M.R. Sant'Ana, J.D. Botezelli, R.S. Gaspar, A.S.R. da Silva, D.E. Cintra, L.P. de Moura, E.R. Ropelle, J.R. Pauli, Physical exercise reduces pyruvate carboxylase (PCB) and contributes to hyperglycemia reduction in obese mice, J. Physiol. Sci. (2017), http://dx.doi.org/10. 1007/s12576-017-0559-3 https://www.ncbi.nlm.nih.gov/pubmed/28710665.

[17] B.D.A. RODRIGUES, L.S.S. PAULI, C.T. DE SOUZA, A.S.R. DA SILVA, D.E.C. CINTRA, R. MARINHO, L.P. DE MOURA, E.C.C. ROPELLE, J.D. BOTEZELLI, E.R. ROPELLE, J.R. PAULI, Acute exercise decreases tribbles homolog 3 protein levels in the hypothalamus of obese rats, Med. Sci. Sports Exerc. 47 (2015) 1613-1623, http://dx.doi.org/10.1249/MSS.0000000000000585.

[18] H. Xu, Q. Yang, M. Shen, X. Huang, M. Dembski, R. Gimeno, L.A. Tartaglia, R. Kapeller, Z. Wu, Dual specificity MAPK phosphatase 3 activates PEPCK gene transcription and increases gluconeogenesis in rat hepatoma cells, J. Biol. Chem. 280 (2005) 36013-36018, http://dx.doi.org/10.1074/jbc.M508027200.

[19] K.W. Kim, J. Donato, E.D. Berglund, Y.-H. Choi, D. Kohno, C.F. Elias, R.A. DePinho, J.K. Elmquist, FOXO1 in the ventromedial hypothalamus regulates energy balance, J. Clin. Invest. 122 (2012) 2578-2589, http://dx.doi.org/10.1172/JCI62848.

[20] K. Iskandar, Y. Cao, Y. Hayashi, M. Nakata, E. Takano, T. Yada, C. Zhang, W. Ogawa, M. Oki, S. Chua, H. Itoh, T. Noda, M. Kasuga, J. Nakae, PDK-1/FoxO1 pathway in POMC neurons regulates Pomc expression and food intake, AJP Endocrinol. Metab. 298 (2010) E787-E798, http://dx.doi.org/10.1152/ajpendo. 00512.2009.

[21] E.R. Ropelle, J.R. Pauli, P. Prada, D.E. Cintra, G.Z. Rocha, J.C. Moraes, M.J.S. Frederico, G. da Luz, R.A. Pinho, J.B.C. Carvalheira, L.A. Velloso, M.A. Saad, C.T. De Souza, Inhibition of hypothalamic Foxo1 expression reduced food intake in diet-induced obesity rats, J. Physiol. 587 (2009) 2341-2351, http://dx.doi.org/10 1113/jphysiol.2009.170050.

[22] P.G. Quaresma, L. Weissmann, T.M. Zanotto, A.C. Santos, A.H. de Matos, I.C. Furigo, F.M. Simabuco, J. Donato Jr, J.C. Bittencourt, I. Lopes-Cendes, P.O. Prada, Int J Obes (Lond) 41 (February (2)) (2017) 268-278, http://dx.doi.org/ 10.1038/ijo.2016.174 Epub 2016 Oct 13. 